International Journal of Modern Physics B,

Vol. 23, No. 27 (2009) 5343

(C) World Scientific Publishing Company

\title{
ERRATUM
}

\section{WHY HOLES ARE NOT LIKE ELECTRONS. III. HOW HOLES IN THE NORMAL STATE TURN INTO ELECTRONS IN THE SUPERCONDUCTING STATE}

\author{
[INT. J. MOD. PHYS. B, Vol. 23, No. 14 (2009) 3035-3057] \\ J. E. HIRSCH \\ Department of Physics, University of California, San Diego \\ La Jolla, CA 92093-0319 \\ jhirsch@ucsd.edu
}

Received 5 October 2009

\begin{abstract}
Bibliographic Ref. 2 of the paper is given as "Phys. Rev. B 71, 104522 (2005), hereafter referred to as II." In several places in the paper where it reads "Sec. 2", it should be replaced by "II". That is, it is a reference to bibliographic Ref. 2 rather than to Sec. 2 of the paper. Specifically, on pages 3039, 3047, 3049 and 3050.

Bibliographic Ref. 1 of the paper is given as "Phys. Rev. B 65, 184502 (2002), hereafter referred to as I." On p. 3047 where it reads "Sec. 1", it should be replaced by "I".
\end{abstract}

